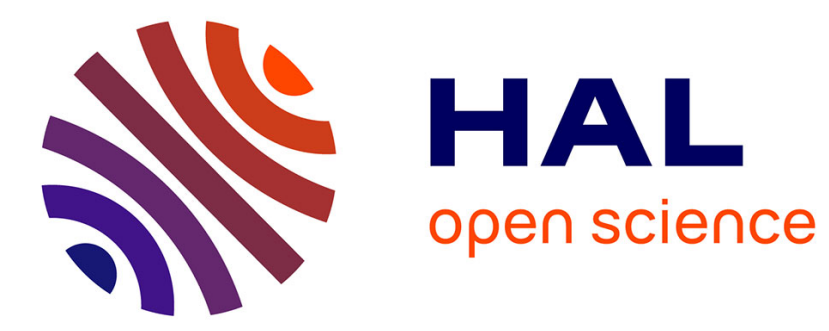

\title{
cMOOC: How to Assist Teachers in Integrating Motivational Aspects in Pedagogical Scenarios?
}

Aicha Bakki, Lahcen Oubahssi, Chihab Cherkaoui, Sébastien George

\section{To cite this version:}

Aicha Bakki, Lahcen Oubahssi, Chihab Cherkaoui, Sébastien George. cMOOC: How to Assist Teachers in Integrating Motivational Aspects in Pedagogical Scenarios?. 1st International Conference on Stakeholders and Information Technology in Education (SAITE), Jul 2016, Guimarães, Portugal. pp.72-81, 10.1007/978-3-319-54687-2_7 . hal-01625379

\section{HAL Id: hal-01625379 \\ https://hal.inria.fr/hal-01625379}

Submitted on 27 Oct 2017

HAL is a multi-disciplinary open access archive for the deposit and dissemination of scientific research documents, whether they are published or not. The documents may come from teaching and research institutions in France or abroad, or from public or private research centers.
L'archive ouverte pluridisciplinaire HAL, est destinée au dépôt et à la diffusion de documents scientifiques de niveau recherche, publiés ou non, émanant des établissements d'enseignement et de recherche français ou étrangers, des laboratoires publics ou privés.

\section{(c)(1)}

Distributed under a Creative Commons Attribution| 4.0 International License 


\title{
cMOOC: How to Assist Teachers in Integrating Motivational Aspects in Pedagogical Scenarios?
}

\author{
Aïcha Bakki ${ }^{1,2}$, Lahcen Oubahssi ${ }^{1}$, Chihab Cherkaoui ${ }^{2}$, and Sébastien George ${ }^{1}$ \\ ${ }^{1}$ UBL, University of Maine, Le Mans, France \\ \{aicha.bakki, lahcen.oubahssi, sebastien.george\}@univ-lemans.fr \\ ${ }^{2}$ Ibn Zohr University, FSA, IRF-SIC Laboratory, Agadir, Morocco \\ c.cherkaoui@uiz.ac.ma
}

\begin{abstract}
From the very beginning of MOOCs, education stakeholders and researchers in the field of technology enhanced learning (TEL) considered closely the issues related to dropout of learners in these environments. In a detailed analysis of this question, several authors pointed out that this dropout is due to a lack of learners' motivation, a lack of learners' engagement, the isolation, etc. These dropout rates can also be associated with inadequate tools, models and mechanisms allowing personalization and/or adaptation of learning activities. According to these studies, a highly promising solution consists in looking to achieve the supporting of learners' motivation and engagement via adaptation of pedagogical scenarios. This paper goes in this direction by examining and trying to analyze the literature around the dropout issue in MOOCs. It mainly focuses on finding some possible solutions to adapt teaching scenarios and therefore motivate learners. More precisely, these solutions are essentially based on the connectivist approach, by taking into account four dimensions of educational activities, that is: aggregation, remixing, repurposing and feed forward.
\end{abstract}

Keywords. cMOOC $\cdot$ MOOC $\cdot$ educational scenario building $\cdot$ connectivism.

\section{Introduction}

The MOOC (Massive Open Online Courses) movement seems to promise a reinvention of online education to reverse the production and dissemination of knowledge [1].

The model of MOOCs constitutes a significant educational innovation, related in particular to massiveness, openness, peer assessment, etc. Massiveness generates serious questions about how to manage large heterogeneous groups. The heterogeneity, in this context, refers to the diversity of those who enroll, an opening to all, without any distinction of: prerequisites, diplomas, language, etc. This suggests, in a certain way, a true "democratization" of access to online resources. In addition, the certification creates new business models [2]. Finally, if a consensus on the benefits of this educational model seems to be established, it generates new questions. The problem- 
atization of these issues create revisited fields, with specific constraints associated to MOOCs, such as: peer assessment, educational scenario building of MOOCs, nature and profiles of learners, motivation and dropout, etc.

The goal of our work is to conceive and develop various tools which consider complementary and plural aspects of online learning, through individual and/or adaptive, collaborative, fun and massive dimensions. Therefore, the perspective of this work is to refine our approach in order to provide models, tools and techniques to assist teachers (pedagogical teams) to improve pedagogical scenarios in MOOCs taking into account further motivation and adaptation issues.

The main purpose of this paper is not to examine the contribution of MOOCs in achieving the guidelines traced at the beginning, but to propose solutions to the new issues raised, especially dropout rates. Indeed, most authors point out a success rate that does not exceed 10\% [3]. We note, however, that dropout in MOOCs differs from classroom-based courses or event-online diploma courses. The research community have explained this difference by the relative isolation of the learner in MOOC environments, the goals of the course or even the qualification of the course (certificate or diploma), etc.

We present in sections 2 and 3 a literature review as follow: an instance of the main fundamentals of MOOCs and educational scenario building concepts in these environments, then we discuss the issues related to dropout. We will analyze synthetically the various causes, issues raised and proposed solutions. In section 4 , we present as a discussion our problematic and positioning related to mentioned work and research.

\section{Research Context}

\subsection{MOOC: Massive Open Online Course}

MOOC is an acronym that can be approached in two different ways. First, regardless of the underlying ideology, MOOCs are essentially a platform [4]. In other words, MOOCs represent a technical support on which courses are hosted. On the other hand, MOOCs designate the courses themselves. The MOOC acronym comprises four terms that represent a divergence in the research community. They assign different meanings to each word, related to learning and/or online education. Anderson [5] gives a short description according to the features of each word. He defines Massive, not only by the large number of participants, but also by the capacity of the MOOC to scale. Scalability refers here to the capacity of the course to expand to large numbers, without causing disruption to any of the components or activities of the educational experience. For Open, he postulates that most MOOCs are open in the sense of allowing participation anywhere, to anyone and are open free for participation. However, MOOCs may or may not be open in the sense of allowing access to course content or in allowing and encouraging open communication of ideas and ideals. 
Moreover, the origins of MOOCs have used acronyms distinguishing a typology of these courses: cMOOCs [6] and xMOOCs [7]. Each of these types of MOOC have their own technological and pedagogical characteristics. As illustrated in Figure 1, xMOOC is most of the time comprising traditional approaches of teaching and learning, it places the teacher as the main leader in the pedagogical scenario process, whereas the cMOOC is more collaborative. It integrates the learner in a dynamic mul-

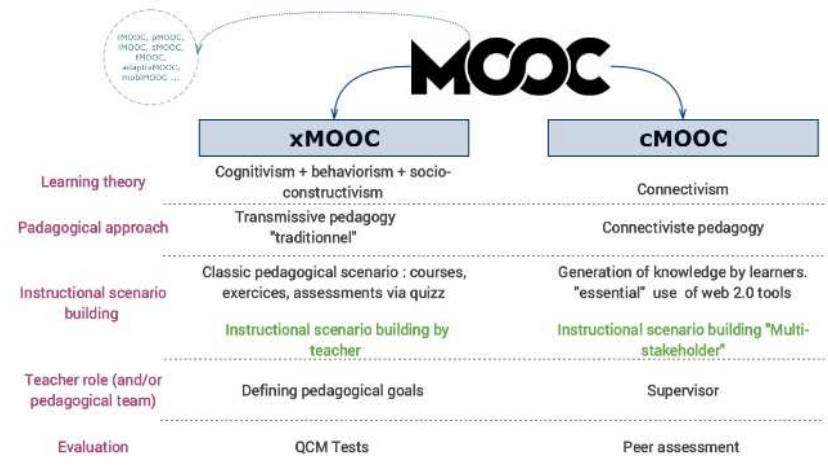

Fig. 1. $\mathrm{xMOOC}$ vs. cMOOC

ti-actors' process of instructional scenario building. According to this, we believe that the $\mathrm{cMOOC}$ offers a search field better adapted to our vision and approach. That consists in providing to the teacher (in this case even learners who can be potential "teachers") resources and services to innovate their pedagogical scenarios to motivated learners.

\subsection{MOOC: Educational Scenario Building}

Educational scenario building is a process of modeling the learning situation. It "is primarily a content design work, resource organization, planning of the activity and mediation to induce and support learning and orchestration" [8]. A scenario implies notions of role, resources, activities and orchestration. It aims to organize and structure the learner's activity, to define the role of each actor and the relationship with the used tools and resources.

To define globally a pedagogical scenario, we transcribe below Pernin and Lejeune's definition: "The learning scenario represents the description, performed a priori or a posteriori, in conducting a learning situation or learning unit for the appropriation of a specific set of knowledge, it has to specify the roles, activities and the knowledge of handling resources, tools, and services related to activities' implementation" [9].

Overall, in the MOOCs, educational scenario building requests innovative and appropriate approaches of teaching and learning to meet the needs of this new concept. It should consider two aspects: massiveness and openness. 
Specifically in cMOOCs, connectivism aims to promote learning through collaboration, production, sharing and creating connections between peers; in almost total openness. In this environment, learners have freedom of choice of learning objectives, from which connections emerge between individuals sharing the same learning objectives. Starting from this point, the connected communities are formed by creating a wealth of resources; personalized courses (paths) are emerging. These paths result from the contributions of each participant and from networks that are formed throughout the course. Such courses are based on four principles: aggregation of information and resources, a reflection on those resources that could be linked to new knowledge, redirecting resources by creating new ones, and finally sharing new resources produced.

Openness of cMOOCs suggests that a pedagogical scenario is not needed and would even go against the underlying principles. Contrary to this assumption, we believe that designing the course connectivists implements educational scenario building practices. Indeed, despite this opening, it seems necessary to establish conditions that are conducive to the emergence of connectivist activities.

The success of a connectivist course suggests promoting and supporting learner autonomy to gain control of their learning and thus promote the creation and emergence of new resources. Autonomy cannot be taken for granted, "It presupposes abilities that all people are not equally capable or willing to mobilize" [10]. Learners must create and produce new resources and knowledge; we believe that they must be guided and oriented during this process to develop and promote their autonomy. In this line, De Figueiredo [11] postulates that:

The dependence of the students from "canned" knowledge and their lack of autonomy, proactivity and initiative has reached unbelievable levels It is vital and urgent to break the vicious circle of dependence and lack of autonomy (...) The use of the technologies has contributed significantly to help manage autonomy. The need to instrument autonomy is also beginning to be understood (...) Once some degree of autonomy is gained, more systematic delegation of assessment can be started, then needs to be instrumented the locus of control may then be gradually transferred to the student to let them participate to the actual development of the course.

As part of connectivism implementation Armatas et al. [12] stipulate that "learning activities are structured to assist students to become independent and autonomous learners while at the same time providing students with opportunities to develop a range of technical and professional skills". From all these points, the need for educational scenario building in these open environments which depends on the learners' production is justified.

The problematization of these findings leads to these questions about the conception process, deployment and adaptation of cMOOCs:

- Which solutions can be provided to teachers to take into account the massiveness of cMOOCs, connectivism principles, the plurality of profiles, the emergence of the educational scenario and finally, the uniqueness of each (course) path? 
- Which tools do we have to provide to teachers to conceive a pedagogical cMOOC-oriented scenario?

- Which tools or dispositives may allow learners to have a control on their learning and also to visualize the scenario and to adapt it according to their needs?

- How can we design an educational scenario building support which takes account of the dynamics, flexibility and opening of cMOOCs while maintaining the learners' autonomy?

\section{Dropout Issue in MOOCs: State of the Art}

Characterizing precisely the dropout issue is not that easy. One of the possible ways that we propose to approach it, follows this plan: possible causes of dropout, different research about the learners' profiles in this environments and proposed solutions to dropout.

Many researchers examined the dropout issue in MOOCs. Clow [13] explains the dropout rate by the demotivation of learners. The view of Cisel [14] covers the initial motivation of the participant. Indeed, he says that the interaction of the participant with the MOOC differs according to his/her post-registration intent and objective. This was supported by Anderson [5], who emphasized that several participants "enroll" just to satisfy their curiosity without any intention to complete the course. Other research is in place around the engagement of learners in a MOOC; we cite in particular the work of Kizilcec et al. [15]. The authors carried out an empirical study about lack of engagement of learners and its causes in MOOCs; but also the lack of interaction between participants using the MOOC. In the same sense, the fact that the participants are isolated is considered by many authors as one of the main reasons behind the weak participants' engagement.

\subsection{Research/Studies on Learners' Profiles}

To examine the issues of dropout in MOOCs, we examined work related to learner profiles in MOOCs. We note the work of Kizilcec et al. [15] and Hill [16] who proposed classifications of learners that interact with the platform. For illustration, we summarize here the work of Hill [16]. In this work a classification of participants in a MOOC according to their degree of involvement in five categories was proposed:

No-Shows - These students appear to be the largest group of those registering for a Coursera-style MOOC, where people register but never login to the course while it is active.

Observers - These students login and may read content or browse discussions, but do not take any form of assessment beyond pop-up quizzes embedded in videos.

Drop-Ins - These are students who perform some activity (watch videos, browse or participate in discussion forum) for a selected topic within the course, but do not 
attempt to complete the entire course. Some of these students use MOOCs informally to find content that helps them meet course goals elsewhere.

Passive Participants - These are students who view a course as content to consume. They may watch videos, take quizzes, read discuss forums, but generally do not engage with the assignments.

Active Participants - These students fully intend to participate in the MOOC and take part in discussion forums, the majority of assignments and all quizzes and assessments.

In a more recent work, Ferguson et al. [17] describe different "clusters" of learners from an empirical study of learners' engagement in different types of MOOCs. The authors define 7 clusters of learners: Samplers, Strong Starters, Returners, Midway Dropouts, Nearly there, Late completers and Keen Completers. These clusters are different according to types of MOOCs. This study shows also that "engagement patterns are related to pedagogy and course duration" [17].

In our view, these classifications are important for several reasons. The first one is to understand the types of MOOC learners and evaluate their engagement. The second is to research methods and practices that can be applied in order to sustain learners' motivation and engagement, and consequently reduce dropout rate. The third reason is to identify specific needs of learners to adapt the content and learning modalities. These are the solutions discussed below.

\subsection{Some Possible Solutions Against Dropout}

Based on a literature review, we can distinguish four different approaches to minimize the dropout rate:

Pedagogical strategies approach. This approach is represented by a number of theoretical strategies validated by empirical studies. Among the pedagogical strategies discussed in the literature, we highlight the work of Williams [18], of adding motivational messages to students when solving mathematics problems on the platform [19]. An example of a message in an activity is: "Remember, the more you practice, the smarter you become". According to this author, this has led to impressive results that were validated in practice. A second strategy is to encourage participants to answer questions and generate explanations before, during and after the activities [18]. Another method is support learners to manage their time on MOOC platforms [2]. This strategy argues that non-experience in e-learning and bad time management involve dropout.

Personalization and/or adaptivity approach. Several research studies focus on the importance of personalization to avoid dropout. In this context, we can mention the PERSUA2MOOC project [20]. This project provides a system for personalization of learning outcomes in MOOCs. PERSUA2MOOC is a project that aims to "adapt" the learning activities considering the individualities and teachers' educational activities. Another interesting work related to personalization is proposed by Williams et al. [21]. The authors propose a platform-independent framework "MOOClet" that allows supporting randomized experimentation and adaptive personalization of content in 
MOOC platforms. Other works, such as Gutiérrez-Rojas et al. [22], present a scheduling algorithm to suggest dynamically the optimum time for learners to learn, considering their profiles, preferences and priorities. This algorithm is implemented by an adaptive scheduler named MyLearningMentor, which provides a sequence of scheduled tasks. Other studies use the model of Felder and Silverman [23] to identify learning styles to provide an adaptive navigation strategy. Another solution is proposed by Cherkaoui et al. [24] with a model of adaptation in Online Learning Environments including MOOC platforms; the aim of this work is to propose an architecture of adaptation model taking into account several dimensions: individual dimension, the massive dimension, the social dimension and the fun dimension.

Gamification approach. Integrating games into the learning process is a solution to capture a larger audience, to motivate and maintain learners' motivation and engagement during the learning activity. Indeed, the coupling of learning, virtual reality and video games allows us to consider the integration of serious games in the online learning process, mentioned in research work [25, 26].

Technological approach. Finally, we note that in addition to video, MOOCs also follow technological ascent, implementing other web2.0 tools, namely, social networks, wikis, forums, etc.

In our view, identifying these works is important for several reasons: (1) compile and analyze the state-of-the-art in MOOC research that has been conducted on dropout issue in MOOCs; (2) identify the methods and practices that are applied in order to reduce dropout rate; (3) conduct research on how to reduce dropout in MOOC environments by investigating new models; and (4) examine the context within which further work can take place by identifying opportunities that lie ahead in this research area and make a significant contribution to future research.

Although many research works have addressed the need to reduce dropout rates in MOOC environments, there is not yet any tangible research that focuses on educational scenario building via a teacher-centered process in particular, by introducing and implementing motivational aspects and practices into pedagogical scenarios.

\section{Our Work: Positioning and Methodology}

The emergence of cMOOCs is constrained by creating favorable conditions and environments for teachers to design their courses and for learners to increase their autonomy.

Our hypothesis lies in the proposal of an adequate process of educational scenario building that is suitable with connectivist aspects. From this point of view, the proposal for cMOOC course authoring tools seems to us a solution to encourage teachers to move towards this model, which to date does not have as much success as the xMOOC.

Our work stems from a need to improve cMOOC environments by supporting the implementation of situations and educational activities based on a connectivist approach through a structured and dynamic pedagogical scenario. We aim to provide conceptual and technical tools for teachers to design pedagogical scenarios, and for 
teachers and students to adapt their scenarios. This is what we describe in the rest of this chapter.

To meet the requirements above, we propose a cMOOC-oriented cycle (Figure 2) that will consider on the one hand the pedagogical scenario building and its implementation. In our context, this process will rebuild the interdisciplinary connections by introducing concrete contexts of application based on the main activities of connectivism (formalization and deployment phases), and, on the other hand, the dynamic adaptation to learners' progression through tools that allow drawing up a progressive, emergent course scenario and knowledge consolidation (adaptation process phase).

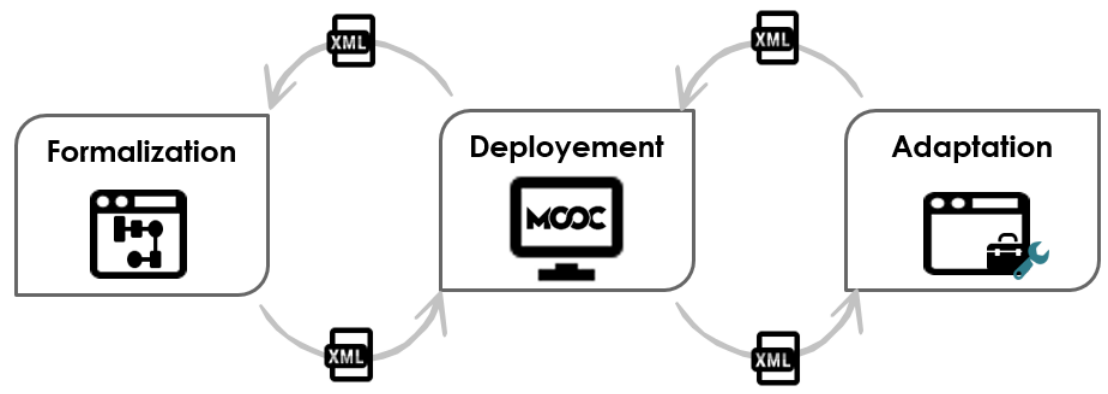

Fig. 2. cMOOC-oriented cycle

1. Formalization: The aim of this phase is to provide teachers with tools and/or models to assist them in the design of formalized cMOOC-oriented scenarios. Our first contribution, arising from these needs, lies in proposing a meta-model of a connectivist pedagogical scenario taking into account the massiveness aspect of cMOOC environments. Our model will be built in several layers. The first level of abstraction is represented by the four activities of connectivism cited previously (aggregation, remixing, repurposing and feed forwarding). Technically, in this phase, we aim to develop a cMOOC-oriented scenario editor in a common language that can be used by different actors involved in the implementation process of learning systems to meet the starting educational intentions all over the design process.

2. Deployment: The aim of this phase is to operationalize pedagogical scenarios in a cMOOC platform. Our contribution lies in the proposal for an operationalization process allowing teachers to create deployable learning scenarios. This phase is to provide a solution (or set of solutions) that allows deployment of pedagogical scenarios generated during the "formalization" phase on a MOOC platform. We will offer elements and services that allow the dynamic implementation of built scenarios: any change on the workflow will be included on the platform and vice versa.

3. Adaptation: This phase is designed to permit compliance with one of the connectivism aspects through our proposal: the learner is an actor of his learning, he is not anymore a consumer of resources but a creator. The learner is dynamically 
involved in the instructional scenario building process. As mentioned above, the educational scenario building process, in connectivist environments, is immersing throughout the learning session. Thus, our objective is to bring solutions to the emergence of needs (motivational, functional, etc.) throughout the learning process. Our contribution is to offer an adaptation model, that takes into account:

- The plurality of profiles, the uniqueness and respect of their personal learning objectives.

- A real-time adaptation solution.

- The possibility of the integration of motivational aspects.

\section{Conclusion}

This paper first presented the two axes related to our work, namely: cMOOCs and educational scenario building in those environments. The synthesis of the literature highlights our views on the approach of dropout along three dimensions: possible causes of dropout, research related to the types of participants and solutions to minimize the dropout rate. The literature review demonstrates that all cited points are complementary and also highlights the importance of motivation as a solution to reduce dropout rate. Analysis of various works highlights several tracks. The objective of our work is to propose an approach, models, methods and techniques to users of MOOCs, to take into account motivation concepts in the design, adaptation and/or personalization of their pedagogical scenarios taking into account specification of cMOOC environments.

\section{References}

1. Glance, D. G., Forsey, M., Riley, M.: The pedagogical foundations of massive open online courses. First Monday, 18(5) (2013)

2. Nawrot, I., Doucet, A.: Building Engagement for MOOC Students, Introducing Support for Time Management on Online Learning Platforms. International World Wide Web Conference Committee (IW3C2) ( 2014)

3. Liyanagunawardena, T. R., Adams, A. A., Williams, S.A.: MOOCs: A systematic study of the published literature 2008-2012, International Review of Research in Open and Distance Learning, 14 (3) 202-227 (2013)16.

4. Schroeder, R., Levin, C.: eduMOOC: Open online learning without limits. Annual Conference on Distance Teaching \& Learning (2012)

5. Anderson, T.: Promise and/or Peril: MOOCs and Open and Distance Education. Commonwealth of Learning (2013)

6. Downes, S.: Places to go: Connectivism \& connective knowledge. Innovate: Journal of Online Education, 5(1) (2008)

7. Hollands, F. M., Tirthali, D.: MOOCs: Expectations and reality. Center for Benefit-Cost Studies of Education, Teachers College, Columbia University, New York, NY. p. 34 (2014) 
8. Henri, F., Compte, C., Charlier, B.: La scénarisation pédagogique dans tous ses débats. PROFETIC, Revue internationale des technologies en pédagogie universitaire, 4(2), 14-24 (2007)

9. Pernin, J. P. :LOM, SCORM et IMS-Learning Design: ressources, activités et scénarios. In actes du colloque «L'indexation des ressources pédagogiques numériques», Lyon (Vol. 16), (2004)

10. Linard, M.: Autoformation, éthique et technologies: enjeux et paradoxes de l'autonomie. Autoformation et enseignement supérieur, 241-263, (2003)

11. De Figueiredo, A.D. :Onlife Learning and the Role of the Stakeholdere. In IFIP TP3 Conference (2016)

12. Armatas, C., Spratt, C., Vincent, A. :Putting connectivist principles into practice: A case study of an online tertiary course. American Journal of Distance Education, 28(2), 81-91, (2014)

13. Clow, D.: MOOCs and the funnel of participation. In: Proceedings of the Third International Conference on Learning Analytics and Knowledge. ACM., pp. 185-189 (2013)

14. Cisel, M.: MOOC: Ce que les taux d'abandon signifient. Blog de Matthieu Cisel (2013)

15. Kizilcec, R. F., Piech, C., Schneider, E.: Deconstructing disengagement: analyzing learner subpopulations in massive open online courses. In: Proceedings of the third international conference on learning analytics and knowledge. ACM, pp. 170-179 (2013)

16. Hill, P.: Some validation of MOOC student patterns graphic. http://mfeldstein.com/validation-mooc-student-patterns-graphic (2013)

17. Ferguson, R., Clow, D., Beale, R.J., Cooper, A., Morris, N., Bayne, S., Woodgate, A.: Moving through MOOCS: Pedagogy, Learning Design and Patterns of Engagement. In: Tenth European Conference on Technology Enhanced Learning (EC-TEL). (2015)

18. Williams, J. J.: Applying Cognitive Science to Online Learning. NIPS Data-Driven Education Workshop (2013)

19. Khan Academy, http://www.KhanAcademy.org

20. Clerc, F. : Mise en Place de la Personnalisation Dans le Cadre des MOOCs. Mémoire de master, Université Claude Bernard Lyon 1 - LIRIS (2014)

21. Williams, J. J., Kim, J., Maldonado, S., Heffernan, N., Li, N., Whitehill, J., Chu, L., Pechenizkiy, M.:The MOOClet Framework: Improving Online Education through Experimentation and Personalization of Modules. (2014)

22. Gutiérrez-Rojas, I., Alario-Hoyos, C., Pérez-Sanagustín, M., Eony, D., Delgado-Kloos, C.: Scaffolding Self-learning in MOOCs. In: Proceedings of the Second MOOC European Stakeholders Summit, EMOOCs, pp. 43-49 (2014)

23. Fasihuddin, H. A., Skinner, G. D., Athauda, R. I.: Boosting the Opportunities of Open Learning (MOOCs) through Learning Theories. GSTF Journal on Computing (JoC), vol. 3, $\mathrm{n}^{\circ} 13$, pp. 1-6 (2013)

24. Cherkaoui, C., Qazdar, A., Battou, A., Mezouary, A., Bakki, A., Er-Raha, B., Mamass, D.: A Model of Adaptation in Online Learning Environments (LMSs and MOOCs). In: Tenth International Conference on Intelligent Systems. (2015)

25. Romero, M., Usart, M.: Serious games integration in an entrepreneurship massive online open course (MOOC). In: Serious Games Development and Applications (pp. 212-225). Springer Berlin Heidelberg (2013)

26. Freire, M., del Blanco, A.,Fernández-Manjón, B.: Serious games as edX MOOC activities. In Global Engineering Education Conference (EDUCON), 2014 IEEE (pp. 867-871) (2014) 